\title{
Influence of shock absorber temperature on vehicle ride comfort and road holding
}

\author{
Nikolay Pavlov ${ }^{1, *}$ \\ ${ }^{1}$ Technical University - Sofia, Faculty of Transport, 8 Kliment Ohridski Blvd., 1000 Sofia, Bulgaria
}

\begin{abstract}
In this work shock absorber damping characteristics at different temperature conditions are determined. The variation of damping properties of the shock absorber depending on the temperature is given. An assessment of ride comfort and road holding characteristics for different temperatures is made.
\end{abstract}

\section{Introduction}

Vehicle dynamic behaviour, ride comfort and tire-road contact are important parts of the design, construction and testing of a vehicle. Research in these areas of automotive engineering has been carried out by many authors in recent years. Some of the most comprehensive books and monographs are [1-4], and the main results and models described by their authors have been taken into account and used in this research work. Shock absorbers heat load and oil temperature are studied in the literature [5-7]. There are no studies how shock absorber temperatures directly influence the vehicle ride comfort. The conditions under which the vehicles are operated depend mainly on four factors: vehicle load, road irregularities character, vehicle speed and ambient temperature [8]. Oscillations of varying frequency and amplitude occur under these various conditions. For most cars, manufacturers set up non-adjustable shock absorbers for good roads, average load (70-80\% of max.), normal speed (moderate) and ambient temperature of $20^{\circ} \mathrm{C}$ (corresponding to standard atmospheric conditions). With this setting, shock absorbers effectively dissipate the vibrations and provide the smallest vertical accelerations of the passenger traveling in vehicle. But in reality the conditions are varied and in practice many combinations are possible which do not meet those assumed by the car maker.

Oil viscosity in the dampers changes when temperature changes. Relatively small temperature changes cause large changes in viscosity. This property of oils can be graphically expressed by the viscositytemperature characteristic. Fig. 1 illustrates how viscosity varies dramatically with temperature over the required operating temperature range [9].

From the viscosity-temperature characteristic it can be seen that when the temperature drops to negative values, the viscosity of the oil increases sharply. At very low winter temperatures, the increased viscosity can cause damage and complete failure of the shock absorber and other chassis components. When big bumps have to be overcome, damage can occur even when the car sets off.

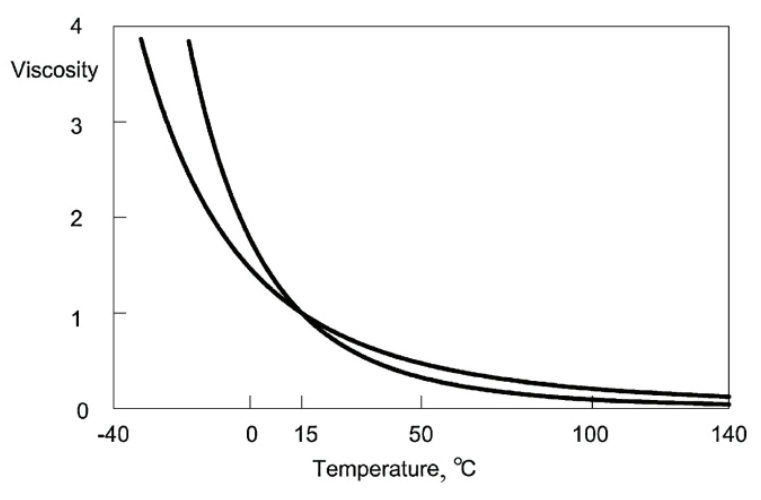

Fig. 1. Mineral oil viscosity relative to its room-temperature viscosity for two types of oil (temperature viscosity sensitivity coefficient $C=2000$ and $3000 \mathrm{~K}$ ) [9].

After hard damping work of the shock absorbers, resistive forces gradually decrease due to oil heating and reduced viscosity, but reaching optimum operating temperature is either too slow or not possible at all and depends mostly on ambient temperature, type of road roughness and speed of the car. At high ambient temperatures and intense damping, the viscosity of the oil greatly decreases, which reduces the effectiveness of the shock absorber as a suspension dissipative element.

The purpose of this work is to study the impact of the shock absorber working temperature on the vehicle ride comfort and tire-road contact.

\section{Factors influencing the working temperature of shock absorbers}

The minimum working temperature of the shock absorber is mainly affected by the air temperature. This temperature depends on the climate specificities of the latitudes in which the vehicles are operated and changes with the seasons. For example, in northern countries such as Canada, Sweden and Norway are characterized by very low temperatures in winter and from low to medium temperatures in the other seasons.

\footnotetext{
* Corresponding author: npavlov@,tu-sofia.bg
} 
For countries located in the equatorial part of the globe and the Mediterranean countries, high temperatures are typical throughout the year. In these two cases, account must be taken of the climate and the dampers are loaded with lower viscosity oils, which are for cold countries and with higher viscosity oils for the warmer countries. More serious is the problem with cars operated in continental climate (countries such as Bulgaria, Serbia, Hungary, etc.), which is characterized by high temperatures in summer and low temperatures in winter, i.e. a large range of annual temperatures (minimum / maximum). The minimum and maximum annual air temperatures in 2016 for the capital of Bulgaria - Sofia are shown in Fig. 2.

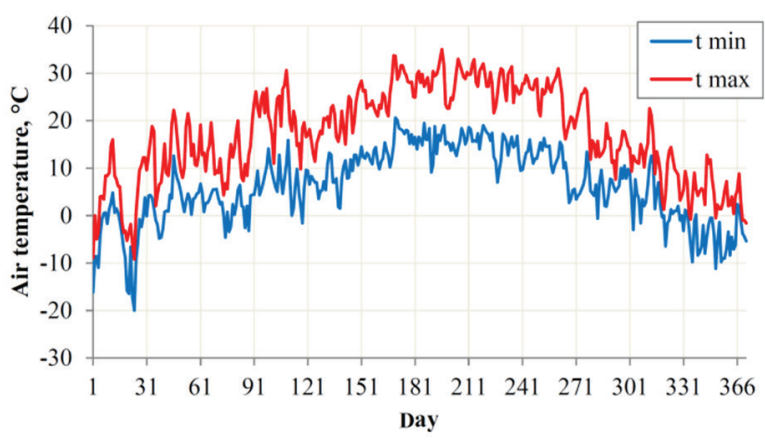

Fig. 2. Air temperature $\left({ }^{\circ} \mathrm{C}\right)$ in 2016 in Sofia [16].

The graph shows that in the coldest month - January (2016) - the minimum temperatures reached $-20^{\circ} \mathrm{C}$. During the warmest month for 2016 - July, the maximum temperatures reached $+35^{\circ} \mathrm{C}$.

At maximum operating temperature, there are other factors that have an impact besides the environment. Depending on the type of road and the characteristics of its unevenness, the dampers work more or less intensively, as this influences their temperature rise. Due to the feature of their being mounted in the vehicle's suspension, they can be blown by the opposite wind more or less. Also, heating depends on the type of shock absorbers used - single-tube or double-tube. Single-tube gas-filled shock absorbers are less heated as the walls of the working cylinders are in direct contact with the air and are cooled better. Although modern hydraulic shock absorbers use hydraulic additives to improve the viscosity-temperature characteristics and synthetic oils developed for lower temperature sensitivity than mineral or vegetable oils, the ideal zero viscous variation cannot be achieved. There are also special designs of valves for temperature compensation, but in many modern shock absorbers they are not used [9].

\section{Shock absorber temperature characteristics}

The temperature characteristic is the dependence of the viscous damping force on the temperature. The temperature range in which the dampers must work is -40 to $+130^{\circ} \mathrm{C}$ [9]. According to [10] the temperature characteristic is recorded for temperatures from -30 to $+100^{\circ} \mathrm{C}$, and according to [11] for temperatures from -50 to $+100^{\circ} \mathrm{C}$. For cars operating on the territory of a continental climate, it can be assumed that the minimum temperatures shown in Fig. 2 must be taken into account and the minimum temperature for testing is taken to be $10^{\circ} \mathrm{C}$.

For the purpose of the present study shock absorbers from two different manufacturers were selected. They are designed to be mounted in the rear suspension of a medium-sized car.

To obtain the temperature characteristics of the shock absorbers we used specialized electro-mechanical shock tester model Shock Dyno - Hi Speed, make from Intercomp ${ }^{\circledR}$ (Fig. 3). The procedure is similar to the one described in $[13,14]$, but the difference is that the temperature varies.

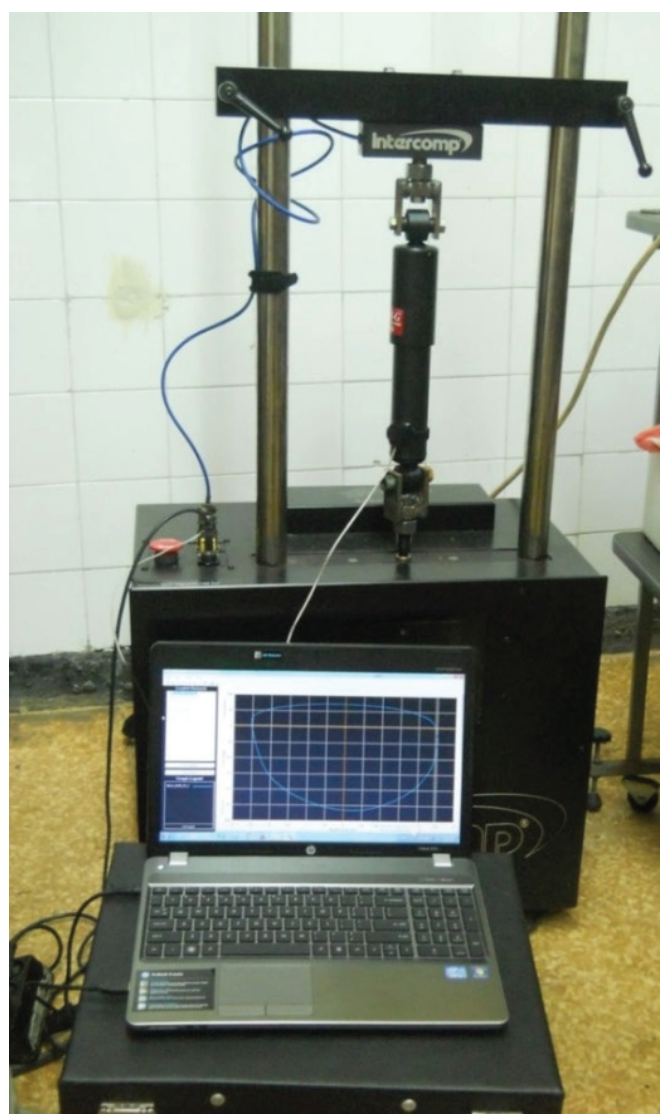

Fig. 3. Shock absorber tester.

The force-displacement characteristics of the shock absorbers obtained during the test are shown in Figures 4 and 5 .

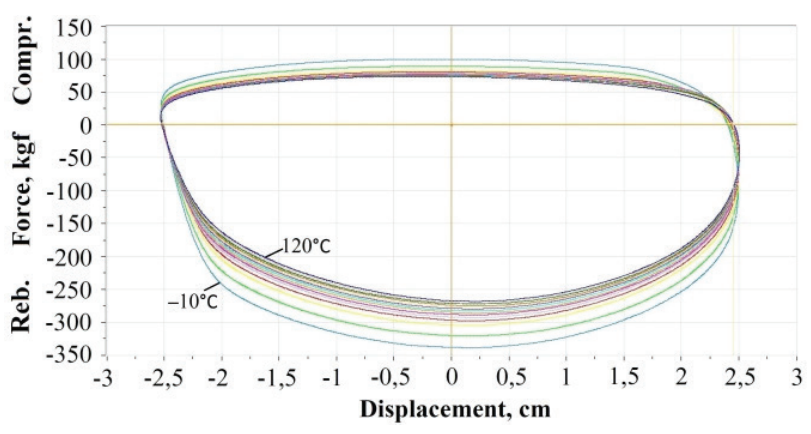

Fig. 4. Force-displacement characteristics of the shock absorber No.1. 


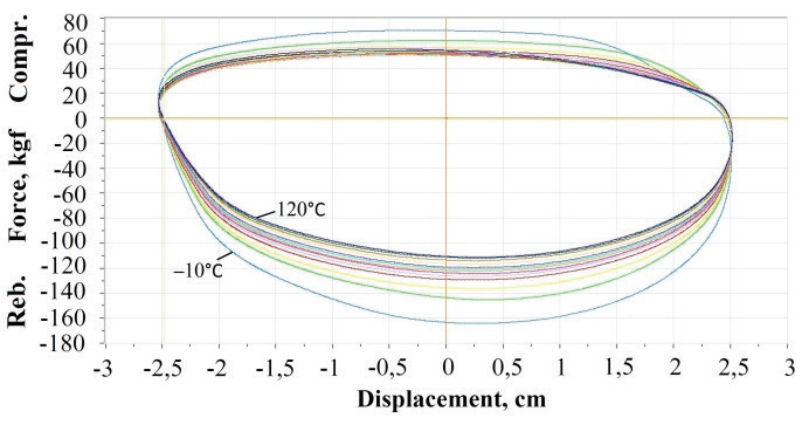

Fig. 5. Force-displacement characteristics of the shock absorber No.2.

From the force-displacement characteristics at different temperature values, the temperature characteristics of the shock absorbers in the range from -10 to $+120^{\circ} \mathrm{C}$ are built, as shown in Figures 6 and 7 .

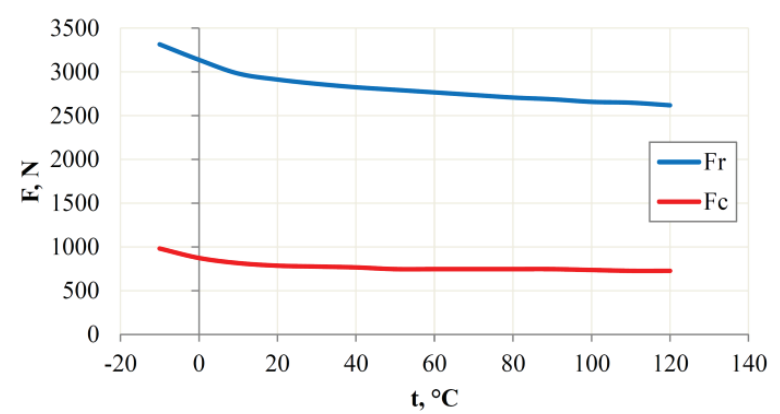

Fig. 6. Temperature characteristic of shock absorber No.1.

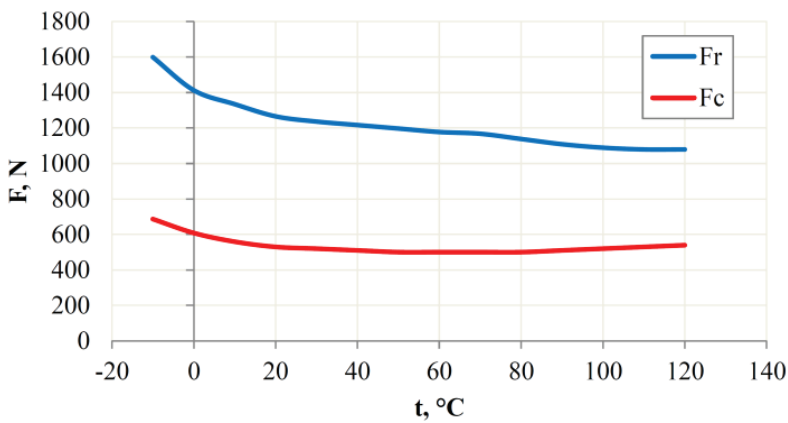

Fig. 7. Temperature characteristic of shock absorber No.2.

The calculation damping coefficient of shock absorber $\beta$, is obtained as the average of the resistive force of the shock absorber $F_{a v}$, divided by the velocity of the piston that should be $0,52 \mathrm{~m} / \mathrm{s}$ for the initial design calculations [12]:

$$
\begin{gathered}
\beta=\frac{F_{a v}}{v} ; \\
F_{a v}=\frac{F_{c}+F_{r}}{2},
\end{gathered}
$$

where $F_{c}$ and $F_{r}$ are respectively the resistance forces of the shock absorber during compression and rebound, N.

The asymmetry ratio is:

$$
k_{a}=\frac{F_{r}}{F_{c}} .
$$

The calculated parameters of the tested shock absorbers for different temperatures are shown in Tables 1 and 2 .

Table 1. Results for shock absorber No.1.

\begin{tabular}{|c|c|c|c|}
\hline $\boldsymbol{t}{ }^{\circ} \mathbf{C}$ & $\boldsymbol{F}_{\boldsymbol{a} \boldsymbol{}}, \mathbf{N}$ & $\boldsymbol{\beta}, \mathbf{( N . s )} / \mathbf{m}$ & $\boldsymbol{k}_{\boldsymbol{a}, \boldsymbol{}}-\boldsymbol{-}$ \\
\hline-10 & 2148,39 & 4131,52 & 3,38 \\
\hline 0 & 2006,15 & 3857,97 & 3,60 \\
\hline 10 & 1898,24 & 3650,45 & 3,66 \\
\hline 20 & 1849,19 & 3556,13 & 3,71 \\
\hline 30 & 1819,76 & 3499,53 & 3,70 \\
\hline 40 & 1795,23 & 3452,37 & 3,69 \\
\hline 50 & 1770,71 & 3405,20 & 3,75 \\
\hline 60 & 1755,99 & 3376,90 & 3,71 \\
\hline 70 & 1741,28 & 3348,61 & 3,67 \\
\hline 80 & 1726,56 & 3320,31 & 3,63 \\
\hline 90 & 1716,75 & 3301,44 & 3,61 \\
\hline 100 & 1697,13 & 3263,71 & 3,61 \\
\hline 110 & 1687,32 & 3244,85 & 3,65 \\
\hline 120 & 1672,61 & 3216,55 & 3,61 \\
\hline
\end{tabular}

Table 2. Results for shock absorber No.2.

\begin{tabular}{|c|c|c|c|}
\hline $\boldsymbol{t} \boldsymbol{~}^{\circ} \mathbf{C}$ & $\boldsymbol{F}_{\boldsymbol{a} \boldsymbol{v}}, \mathbf{N}$ & $\boldsymbol{\beta}, \mathbf{( N . s )} / \mathbf{m}$ & $\boldsymbol{k} \boldsymbol{a},{ }^{-}$ \\
\hline-10 & 1142,87 & 2197,82 & 2,33 \\
\hline 0 & 1010,43 & 1943,13 & 2,32 \\
\hline 10 & 946,67 & 1820,51 & 2,39 \\
\hline 20 & 897,62 & 1726,18 & 2,39 \\
\hline 30 & 878,00 & 1688,45 & 2,38 \\
\hline 40 & 863,28 & 1660,15 & 2,38 \\
\hline 50 & 848,57 & 1631,86 & 2,39 \\
\hline 60 & 838,76 & 1612,99 & 2,35 \\
\hline 70 & 833,85 & 1603,56 & 2,33 \\
\hline 80 & 819,14 & 1575,26 & 2,27 \\
\hline 90 & 809,33 & 1556,39 & 2,17 \\
\hline 100 & 804,42 & 1546,96 & 2,09 \\
\hline 110 & 804,42 & 1546,96 & 2,04 \\
\hline 120 & 809,33 & 1556,39 & 2,00 \\
\hline
\end{tabular}

\section{A numerical study of ride comfort and road holding for different shock absorber temperatures}

1DOF and 2DOF models of the quarter car are used to determine the comfort and tire-road contact at different shock absorber operating temperatures. The simplest model is the one with 1 degree of freedom (Fig. 8, a). It takes into account the unsprung mass $m$ acting on one wheel ( $1 / 4$ of the car mass).

More complex is a dual mass model with two degrees of freedom (Fig. 8, b). It consists of two bodies - sprung mass $m$ and unsprung mass $m_{t}$ and two elastic elements $c$ and $c_{t}$, representing respectively the elasticity of the spring and tire elasticity. Dissipative elements are $\beta$ and $\beta_{t}$ and represent the shock absorber and tire dissipation. Through this model we receive results for the characteristics of the sprung and unsprung masses.

The basis of the method is Lagrange equation of the second order:

$$
\frac{d}{d t}\left(\frac{\partial \mathrm{T}}{\partial \dot{q}_{i}}\right)-\left(\frac{\partial \mathrm{T}}{\partial q_{i}}\right)+\left(\frac{\partial U}{\partial q_{i}}\right)+\left(\frac{\partial R}{\partial \dot{q}_{i}}\right)=Q,
$$


where $\mathrm{T}$ and $\mathrm{U}$ are the kinetic and potential energy of the system; $R$ - Rayleigh dissipation function; $q_{i}, \dot{q}_{i}$ - vector of generalized coordinates and velocities; $Q$ - kinematic disturbance; $t$ - time.

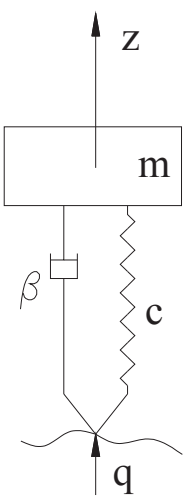

a)

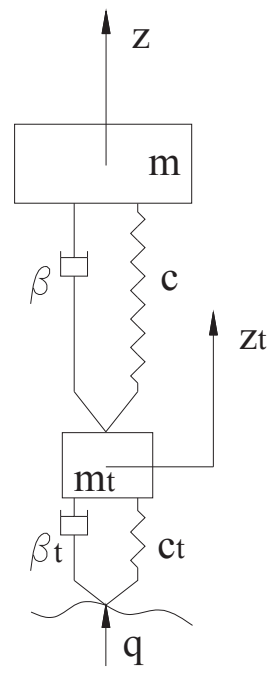

b)
Fig. 8. 1DOF (a) and 2DOF (b) quarter car model.

The numerical simulations were carried out in MATLAB with sprung mass $m=350 \mathrm{~kg}$, unsprung mass $m_{t}=30 \mathrm{~kg}$, spring ratio of the spring is $c=20 \mathrm{kN} / \mathrm{m}$, tire spring ratio $c_{t}=150 \mathrm{kN} / \mathrm{m}$, shock absorbers damping parameters as given in Tables 1 and 2, tire damping $\beta_{t}=50 \mathrm{~N} . \mathrm{s} / \mathrm{m}$.

The results from the numerical experiments for 1DOF dynamic model are shown in Figures 9 to 12, and for 2DOF dynamic model are shown in Figures 13 to 20.

The free oscillation step response of shock absorber No.1 and No.2 are shown in Figures 9 and 10.

The forced vibrations for the 1DOF model are shown in Figures 11 and 12.

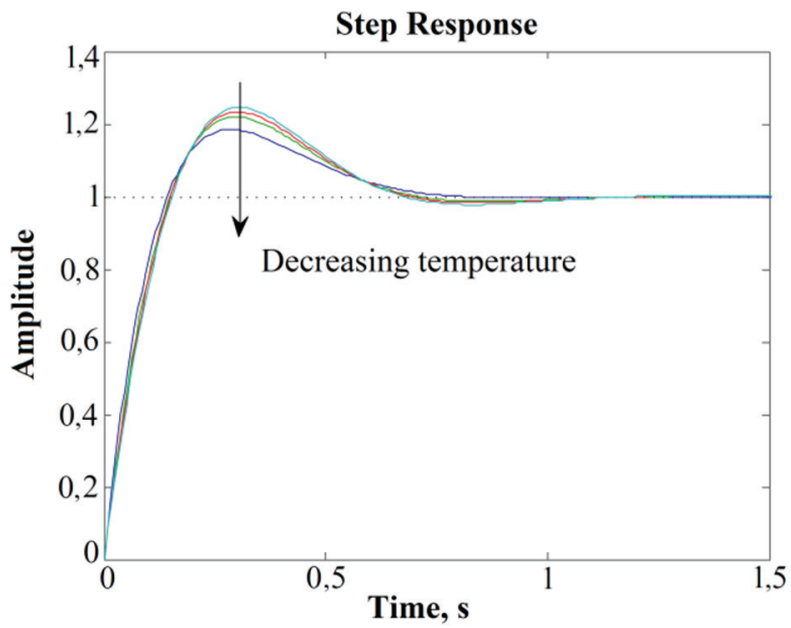

Fig. 9. Oscillogram of 1DOF model damping oscillations at different temperatures of shock absorber No.1.

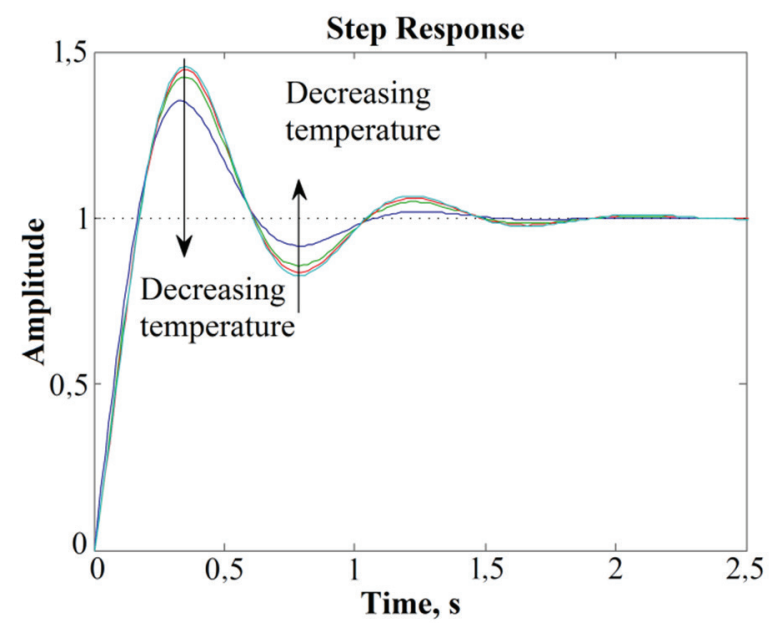

Fig. 10. Oscillogram of 1DOF model damping oscillations for different temperatures of shock absorber No.2.

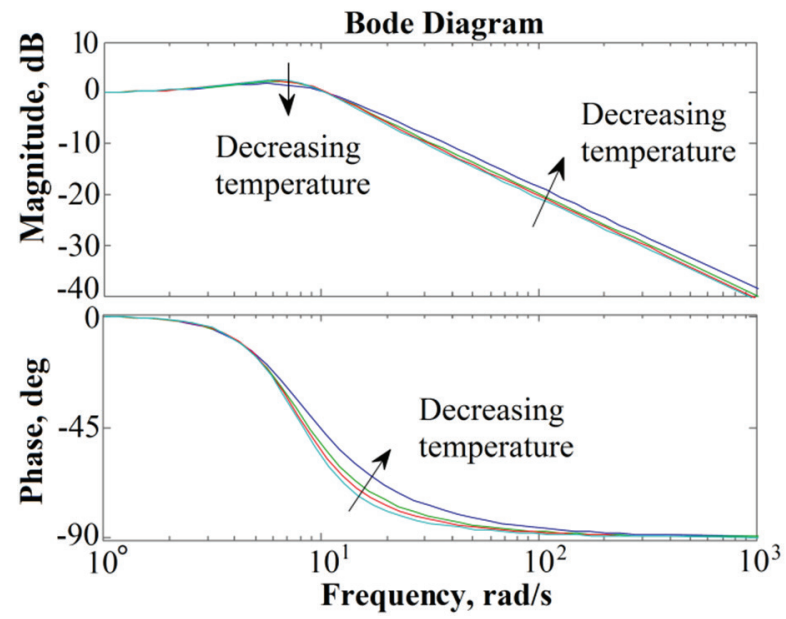

Fig. 11. Amplitude-frequency and phase-frequency response of 1DOF model at different temperatures of shock absorber No.1.

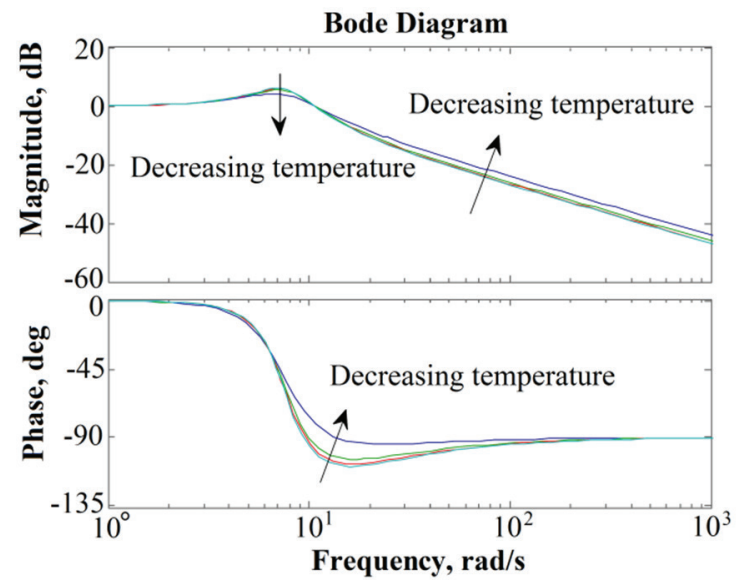

Fig. 12. Amplitude-frequency and phase-frequency response of 1DOF model at different temperatures of shock absorber No.2.

The results from the $2 \mathrm{DOF}$ model for random vibrations acceleration spectral density (ASD) are given in Figures 13 to 16. Excitation characteristics are typical of pavement in good condition.

A decrease in the temperature increases the shock absorber damping coefficient. As a result there is an 
increase in the accelerations of the sprung mass in the resonant and the post-resonant region for the shock absorber No.1 (Fig. 13). The rise of spectral density from $20^{\circ} \mathrm{C}$ to $-10^{\circ} \mathrm{C}$ is about $20 \%$, and the difference between spectral densities in a temperature range of -10 to $120^{\circ} \mathrm{C}$ is about $40 \%$. A reduction in the damping coefficient in high temperatures improves the ride comfort in postresonance band for both shock absorbers.

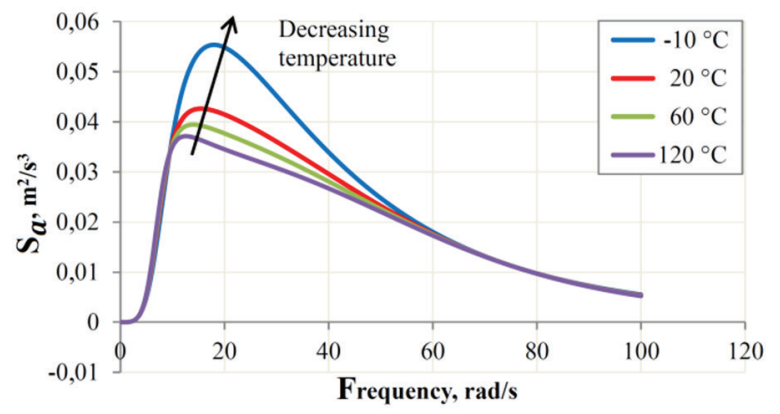

Fig. 13. Spectral density of acceleration of the sprung mass at different temperatures of shock absorber No. 1.

There is an increase of the spectral density in the postresonant region for shock absorber No. 2, but reduction of acceleration in the resonant region (Fig. 14).

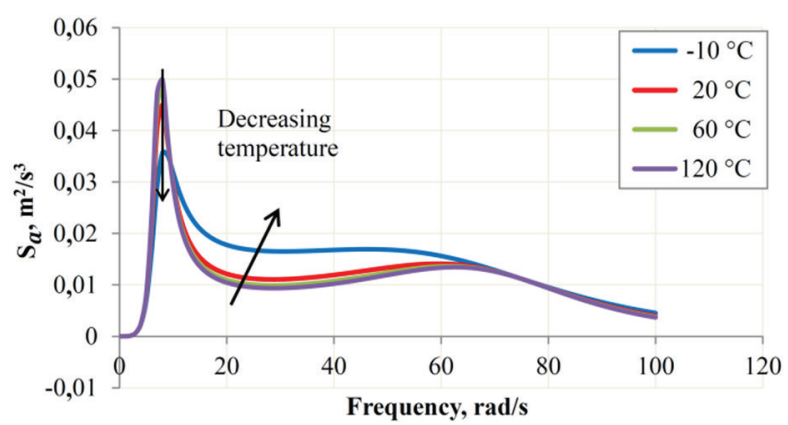

Fig. 14. Spectral density of acceleration of the sprung mass at different temperatures of shock absorber No. 2.

By accelerating the unsprung masses (Figures 15 and 16) we can notice a significant reduction (of over $40 \%$ from $120^{\circ} \mathrm{C}$ to $-10^{\circ} \mathrm{C}$ ) in the high rates of damping (low temperatures) to a given frequency range. The most obvious thing is the reduction of the accelerations at the resonant frequency of these masses for both shock absorbers. Small accelerations testify to small intensity of vibration of the wheels. That means better contact between tire and road.

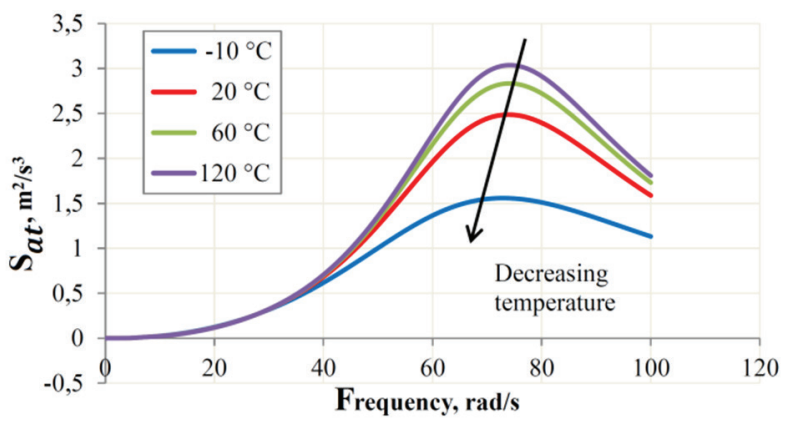

Fig. 15. Spectral density of acceleration of the unsprung mass at different temperatures of shock absorber No. 1.

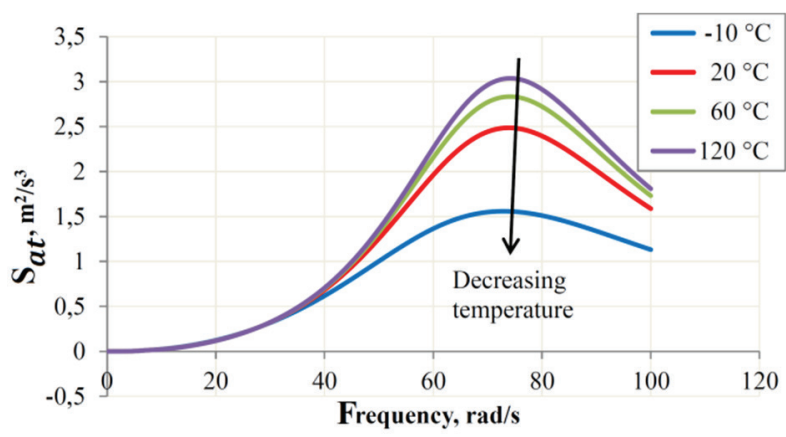

Fig. 16. Spectral density of acceleration of the unsprung mass at different temperatures of shock absorber No. 2.

This analysis demonstrated conflicting demands on damping and the need to reduce coefficient $\beta$ for maximum comfort and increase it when we need maximum contact between tire and road.

As can be seen from the graph in Figures 17 and 18, there is a fall by about $10 \%$ in the root mean square (RMS) of vertical acceleration of the sprung masses for both shock absorbers and a rise of unsprung mass RMS by about $25 \%$ for shock absorber No. 1 and by $30 \%$ for shock absorber No. 2.

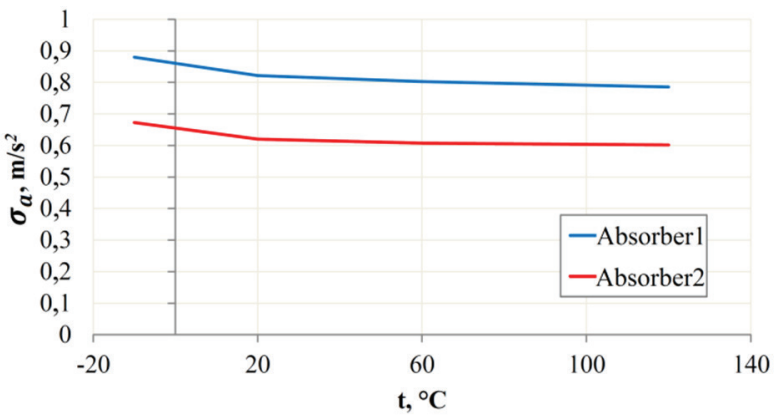

Fig. 17. RMS value of the vertical acceleration $\sigma_{a}$ of the sprung mass of shock absorbers No. 1 and No. 2.

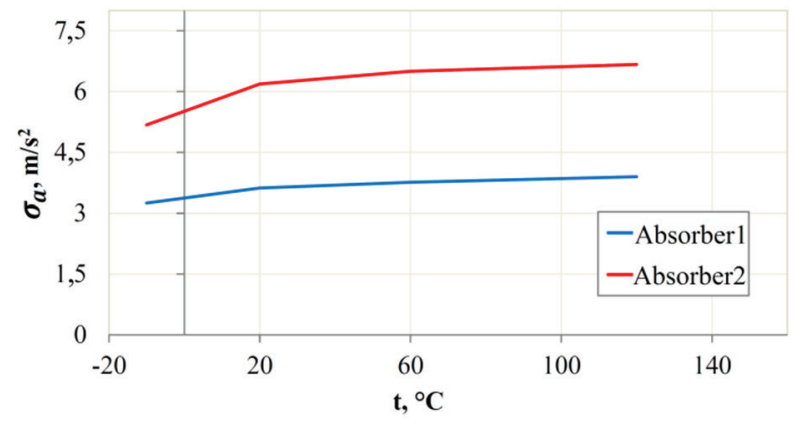

Fig. 18. RMS value of the vertical acceleration $\sigma_{a}$ of the unsprung mass of shock absorbers No. 1 and No. 2.

An example of the assessment and comparison of vertical acceleration of sprung mass for different shock absorber temperatures, according to the ISO standard for whole-body vibration, is shown in Fig. 19. For the simulation was used sinus excitation with an amplitude equal to $1,1 \mathrm{~cm}$, corresponding to asphalt with good quality, and frequency from 1 to $100 \mathrm{~Hz}$. In the same frequency range was studied the vibration of the unsprung 
mass with damping parameters for shock absorbers No.1 and No.2 (Fig. 20). At higher amplitude of irregularities, more noticeable differences in RMS values can be achieved for the different temperature conditions.

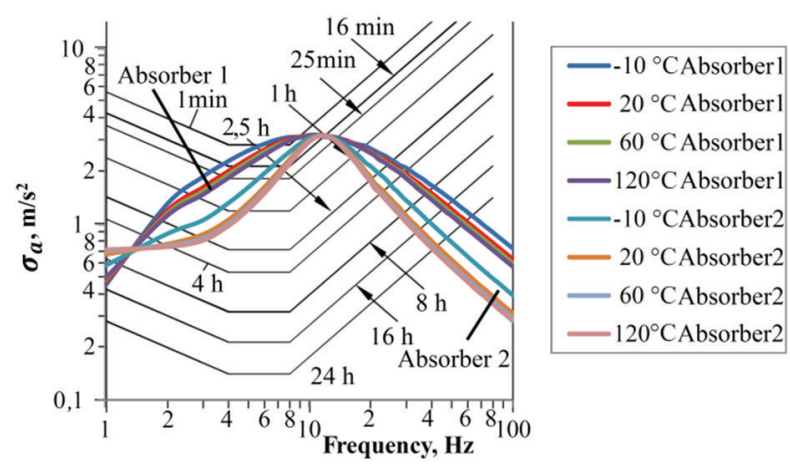

Fig. 19. RMS value of the vertical acceleration $\sigma_{a}$ of the sprung mass of shock absorbers No.1 and No.2 according to ISO 2631-1 (1985) [15].

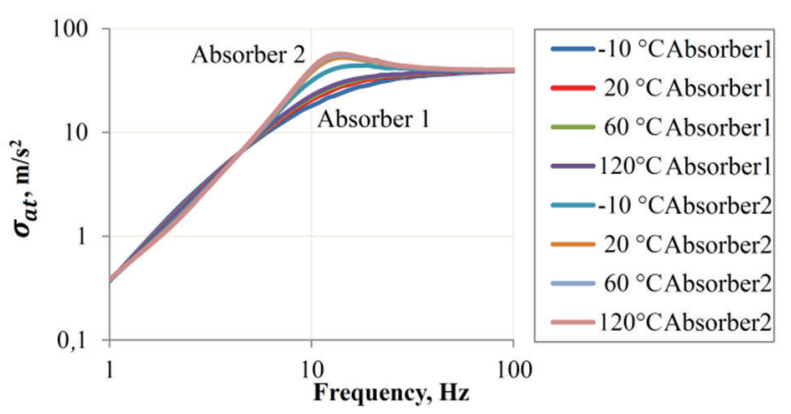

Fig. 20. RMS value of the vertical acceleration $\sigma_{a}$ of the unsprung mass of shock absorbers No.1 and No.2.

\section{Conclusion}

The present study examines the impact of shock absorber temperature on vehicle ride comfort and road holding. For this purpose, shock absorbers temperature characteristics were obtained. The results were used for numerical simulations with $1 \mathrm{DOF}$ and $2 \mathrm{DOF}$ quarter car models. On the basis of the simulation, the conclusion can be drawn that a decrease in temperature of up to $-10^{\circ} \mathrm{C}$ does influence the ride comfort of vehicles, expressed in growth in spectral density of vertical acceleration (ASD) in the resonant and the post-resonant region with $20 \%$ in comparison with the acceleration at $20^{\circ} \mathrm{C}$. Similarly $20 \%$ fall is observed between ASD at $120^{\circ} \mathrm{C}$ in comparison with the ASD at $20^{\circ} \mathrm{C}$. For ASD of the unsprung masses there is over $40 \%$ reduction in values at $-10^{\circ} \mathrm{C}$ in relation to values at $120^{\circ} \mathrm{C}$. There is $25-30 \%$ rise in $\mathrm{RMS}$ of vertical acceleration of the unsprung masses for temperature interval between $-10^{\circ} \mathrm{C}$ and $120^{\circ} \mathrm{C}$. As well $10 \%$ fall for RMS of the sprung masses in the same temperature interval. Assessment of vertical acceleration RMS value of sprung mass according to the ISO standard tolerance curves at different temperatures is made.

\section{References}

1. G. Genta, L. Morello, The automotive chassis, Vol. 2: System design, Springer, (2009)

2. G. Genta, Vibration dynamics and control, Springer, (2009)

3. M. Mitschke, H. Wallentowitz, Dynamik der Kraftfahrzeuge, Springer, (2014)

4. M. Demić, Optimizacija oscilatornih sistema motornih vozila, Mašinski Fakultet, Kragujevac, (1997)

5. M. Demić, D. Diligenski, Numerical simulation of shock absorbers heat load for semi-active vehicle suspension system. Thermal Science, 20(5), 17251739, (2016)

6. M. Demić, D. Diligenski, M. Milovanović, A contribution to research of the influence of degradation of vehicle vibration parameters on thermal load of shock absorbers. Journal of Applied Engineering Science, 11(1), 23-30, (2013)

7. K. Reif, K. Schmidt, F. Schimmack, F. Niedermeier, N. Kennes, Estimation of the oil temperature in adjustable vibration dampers, ATZ Worldwide, 112(3), 22-27, (2010)

8. K. Kosev, Hydraulic shock-absorbers for motorcar and motorcycles. Technica Publishing, Sofia, in Bulgarian, (1976)

9. J. Dixon, The shock absorber handbook. Wiley,(2007)

10.Telescopic Hydraulic shock absorbers for automobiles - bench test methods, Standardization Publishing, Sofia, in Bulgarian, (1983)

11. GOST R 53816-2010, Vehicles. Hydraulic telescopic shock absorbers. Technical requirements and test methods, Standardinform, Moskow, in Russian, (2010)

12. B. Heißing, Chassis handbook: fundamentals, driving dynamics, components, mechatronics, perspectives, Vieweg+Teubner Verlag, (2011)

13. N. Pavlov, A method and test equipment for obtaining characteristics of controlled hydraulic shock absorbers, EKO Varna, 41-47, in Bulgarian, (2015)

14. N. Pavlov, E. Sokolov. Vibration characteristics of quarter car semi-active suspension model - numerical simulations and indoor testing, Trans Motauto World, 2(1), 11-16, (2017)

15. ISO 2631-1. Evaluation of human exposure to wholebody vibration - part 1: general requirements. Geneva: International Organization for Standardization, (1985)

16. http://www.stringmeteo.com/ (10 August 2017) 